\title{
Aproximación a la funcionalidad en traducción literaria
}

\author{
Cristina Huertas Abril \\ Universidad de Córdoba \\ 152huabc@uco.es
}

Recibido: 25 de noviembre de 2011

Aceptado: 5 de marzo de 2012

\section{RESUMEN}

Este trabajo propone una aproximación a las teorías funcionalistas para aplicarlas en el ámbito de la traducción literaria, con el fin de complementar otros modelos ya afianzados como el lingüístico o el filológico, por citar tan solo dos de ellos. Para ello, revisaremos el concepto de traducción literaria, lo que nos permitirá justificar la funcionalidad, así como estudiar el modelo de comunicación literaria propuesto por Nord. Se estudian también las principales críticas realizadas a la teoría del escopo (Skopostheorie), exponiendo la justificación teórica que demuestra la pertinencia y eficacia de los enfoques funcionalistas para la traducción literaria.

Palabras clave: Estudios sobre la Traducción, traducción literaria, enfoques funcionalistas, traducción y funcionalismo.

\section{An Approach to Functionalism in Literary Translation}

\begin{abstract}
This paper proposes an approach to functionalist theories in the field of literary translation, in order to complement well-established models, such as the linguistic and the philological approaches. The concept of literary translation will be reviewed, by which we will be able to justify the relevance of functionalism, as well as to study Nord's literary communication model. Moreover, we will analyse the main criticisms to the Skopostheorie, explaining the theoretical justification to show its relevance and effectiveness for literary translation.
\end{abstract}

Keywords: Translation Studies, literary translation, functionalist approaches, translation and functionalism.

Sumario: 1. Introducción. 2. El concepto de traducción literaria. 3. La funcionalidad en traducción literaria. 4. Críticas a la aplicación de las teorías funcionalistas a la traducción literaria. 5. Conclusión. 6. Referencias bibliográficas. 


\section{Introducción}

La traducción es un acto de comunicación, si bien no cabe duda de que como señala Sánchez (2009: 123) "literary translation covers an enormous semantic and stylistic field whose dimensions are practically imposible to measure in any precise form". Por ello, no es de extrañar que la traducción literaria sea la tipología que tradicionalmente haya condicionado los criterios de traducibilidad. Asimismo, la traducción literaria determina a su vez que las propias tipologías de traducción no puedan establecerse para solventar problemas lingüísticos concretos, sino que en realidad sólo pueden establecerse de acuerdo con la teoría que cada acto de traducción -de manera independiente- lleva implícita. No obstante, antes de abordar el concepto de traducción literaria, consideramos de gran importancia hacer alusión a las principales características del lenguaje literario. En primer lugar, y como señala Aguiar e Silva (1975: 16ss), en el lenguaje literario destaca la función poética:

La función poética del lenguaje se caracteriza primera y esencialmente por el hecho de que el mensaje crea imaginariamente su propia realidad por el hecho de que la palabra literaria, a través de un proceso intencional, crea un universo de ficción que no se identifica con la realidad empírica (...). Entre el mundo imaginario creado por el lenguaje imaginario y el mundo real siempre hay vínculos, pues la ficción literaria no se puede desprender jamás de la realidad empírica. No se trata de una deformación del mundo real, pero sí de la creación de una realidad nueva, que mantiene siempre una relación de significado con la realidad objetiva.

La segunda característica destacable consiste en que el lenguaje literario es connotativo, pues los diferentes términos presentan, junto a aquello a lo que habitualmente hacen referencia, otros elementos presentes en el lector $-\mathrm{y}$ en su caso, en el traductor-. El lenguaje connotativo se opone al denotativo, frecuentemente utilizado, por ejemplo, en el discurso científico o jurídico.

La configuración representativa del signo verbal no se agota en un contenido intelectual, ya que presenta un núcleo informativo rodeado e impregnado de elementos emotivos y volitivos. (...) Las cargas connotativas de un vocablo dependen en alto grado del siquismo de los hablantes y de los contextos en que el vocablo es emitido y/o recibido (Aguiar e Silva 1975: 18).

A tenor de lo expuesto anteriormente, y considerando la importancia de la función poética, así como el aspecto connotativo del lenguaje literario podemos afirmar que el lenguaje literario es claramente plurisignificativo. Aguiar e Silva (1975: 20) explica esta característica del siguiente modo:

El lenguaje literario es plurisignificativo porque, en él, el signo lingüístico es portador de múltiples dimensiones semánticas y tiende a una multivalencia significativa, huyendo del significado unívoco, que es propio de los lenguajes monosigni- 
ficativos. (...) Por otro lado, importa subrayar que la plurisignificación literaria se constituye a base de los valores literales y materiales de los signos lingüísticos; es decir, el lenguaje literario conserva y trasciende simultáneamente la literalidad de las palabras.

Por otra parte, el lenguaje literario se aleja de los hábitos lingüísticos de manera que mediante el uso de recursos retóricos como las metáforas u otras figuras estilísticas, el escritor transgrede las normas lingüísticas, convirtiendo así el lenguaje habitual en literario:

El lenguaje literario (...) se define por la recusación intencionada de los hábitos lingüísticos y por la exploración inhabitual de las posibilidades significativas de una lengua. (...) El escritor percibe los seres y los acontecimientos de un modo inédito a través de una especie de 'deformación creadora', y este deseo de 'tornar extraño' se manifiesta claramente en el lenguaje literario (Aguiar e Silva 1975: 24).

A estas características propias del lenguaje literario hemos de añadir el hecho de que como afirma Jones (2011: 152) "texts are often popularly viewed as either literary or non-literary, implying that literatura should be sean as a large "super-genre"'. Esta gran división tradicional entre traducción literaria y traducción especializada - 0 no literaria- se fundamenta principalmente en que a pesar de que comparten algunos de los principales problemas traductológicos ${ }^{1}$ (estructuras gramaticales, tiempos verbales, marcadores del discurso, etc.), la segunda no debe manifestar tipo alguno de ambigüedad o dobles sentidos, mientras que como hemos visto en lo establecido por Aguiar e Silva la traducción literaria tiene en la connotación una de sus características más destacadas.

\section{El concepto de traducción literaria}

Las primeras teorías específicas sobre traducción se publican en la década de 1950 gracias a especialistas tan estudiados como Jakobson, y Vinay y Darbelnet, si bien las reflexiones acerca del proceso traslativo derivan de la traducción de textos literarios y sagrados que tienen en cuenta tanto las relaciones interculturales como las dificultades lingüísticas inherentes al TO. No obstante, la propia combinación de los términos "traducción" y "literaria" nos conduce al primer escollo para comprender el concepto, puesto que ninguno de ellos es simple o está bien definido en la mayoría de las culturas. De este modo, tradicionalmente

${ }^{1}$ Siguiendo la definición de Cruces Collado (2001: 814): "De modo genérico, se puede definir el error de traducción, (aquel que se detecta en un texto, en tanto que traducción) como una ruptura de las reglas de coherencia de un TT, sean éstas de tipo gramatical, de combinabilidad léxica, congruencia semántica o de conformidad al conocimiento del mundo y de la experiencia acumulada". 
se ha confundido la traducción de obras literarias con otros conceptos, como sería el caso de "adaptación"2 o incluso de "reescritura"3.

Son numerosas las aproximaciones al concepto de "traducción literaria", si bien en primer lugar destacamos la propuesta de Toury (1993: 12s) quien afirma que puede hacer alusión a dos aspectos claramente diferenciados, si bien claramente relacionados entre sí: por una parte, la traducción de textos considerados como literarios en la cultura original; por otra, la traducción de textos que se consideren literarios en el marco de la cultura meta ${ }^{4}$. No obstante, esta segunda situación no es habitual pues normalmente aquel texto que sea literario en la LO también lo será en la LM, y viceversa, de manera que ambos tendrán una posición similar en la cultura origen y en la meta.

Si atendemos a la entrada dedicada a la traducción literaria en la primera edición de la Routledge Encyclopedia of Translation Studies (Bush, 2001: 127), podemos apreciar que primeramente se hace mención directa a la propia actividad traductora, pues se establece que es "an original subjective activity at the centre of a complex network of social and cultural practices". En este sentido, y teniendo en cuenta dicha red de prácticas socioculturales, el traductor literario ha de afrontar, de manera tanto implícita como explícita, el estatus de la obra en su cultura original y, por consiguiente, cruzar los límites de la nacionalidad de la cultura dada ${ }^{5}$, así como adoptar el concepto de la "muerte del autor" de Barthes ${ }^{6}$. La traducción literaria como resul-

${ }^{2}$ La Routledge Encyclopedia of Translation Studies (2011: 3) define este término del siguiente modo: "Adaptation may be understood as a set of translative operations which result in a text that is not generally accepted as a translation but is nevertheless recognized as representing a source text. As such, the term may embrace numerous vague notions such as appropriation, domestication, imitation, rewriting, and so on. Strictly speaking, the concept of adaptation requires recognition of translation as non-adaptation, a somehow more constrained mode of transfer".

3 Este concepto acuñado por Lefevere se define en la Routledge Encyclopedia of Translation Studies (2011: 241) como: "The theory of rewriting proposed by André Lefevere (1945-96) draws on systemic / descriptive approaches and treats translation as a discursive activity embedded within a system of literary conventions and a network of institutions and social agents that condition textual production".

4 Esta propuesta conlleva la dificultad de clasificar el TO y su traducción como dos textos que pertenecerían además a dos géneros diferentes, por lo que podríamos afirmar que estaría directamente relacionado con el concepto de traducción heterofuncional defendido por Nord (1996: 93), quien afirma: "La traduccióninstrumento incluye la traducción equifuncional (que tiene las mismas funciones comunicativas que el texto original), la traducción heterofuncional, cuyas funciones difieren de las del original aunque no tanto como para ser incompatibles, y la traducción 'homóloga' de poesía (...). Como se ve, el enfoque funcional abarca muy variadas formas de 'transferencia intercultural de textos' sin tener que distinguir entre 'traducciones' (en sentido estricto) y 'adaptaciones"”. La traducción heterofuncional, de este modo, consistirá en trasladar significados, tanto de forma intralingüística como interlingüística, adaptándolos a los objetivos comunicativos del receptor.

5 La traducción de textos literarios supone un punto de convergencia y unión entre culturas, puesto que viene a llenar vacíos que, de otro modo, no se cubrirían.

6 Barthes con sus ensayos "La mort de l'auteur" y "Qu'est-ce qu'un auteur ?” rompe con la crítica literaria tradicional, que basaba las interpretaciones de las obras literarias en buena medida en la biografía e intencionalidad de los autores. Barthes (1984: 69), sin embargo, defiende que "la naissance du lecteur doit se payer de la mort de l'auteur", pues será el lector quien reescriba el texto por sí mismo, esto es, quien haga su propia lectura. Esta idea se encuentra muy próxima a la de Paul Valéry (1988: 1191), que establece que: "Mon intentionn'est que mon intention, et l'œuvre est l'œuvre". 
tado es, por tanto, el fruto derivado de la toma de decisiones del traductor, que ha de adoptar una serie de estrategias entre las que destacan, sin duda alguna, la lectura repetida del texto así como una documentación exhaustiva del $\mathrm{TO}^{7}$, con el fin de comprender el estilo y los recursos literarios del TO antes de plasmarlo en el TM.

En cualquier caso, sea cual sea la estrategia elegida, es imprescindible tener en cuenta que el resultado final, el TM, es fruto de numerosas lecturas y borradores, ante los cuales se han de tomar un gran número de decisiones, que preceden, determinan y condicionan la traducción. De este modo, vamos acercándonos más a la definición del proceso, pues como señala Bush (2001: 129), "literary translation is then a very social, culturally-bound process where the translator plays a key role in a complex process of interactions". El traductor se ha de enfrentar a una obra en LO en la cual se debe introducir completamente con el fin de trasvasarla a un entorno lingüístico y cultural diferente. Es esta una tarea compleja, pues ha de introducirse asimismo en el mundo imaginativo del autor, que surge de una experiencia vital en el entorno propio de la lengua y cultura origen, y que diferirán del entorno de la LM. El traductor, por tanto, debe entender perfectamente el TO y comprender su mensaje, ya que el problema fundamental al que se deberá enfrentar será la búsqueda de la equivalencia en el TM, para que éste se comprenda de forma coherente en la cultura meta.

En la segunda edición de la Routledge Encyclopedia of Translation Studies, Jones (2011: 153) establece un triple enfoque para abordar el concepto de traducción literaria: "translation as text, translating processes, and links with social context". Resulta especialmente interesante esta última consideración, a la que Bush apenas hace referencia. Al tratarse de un medio de comunicación interlingüística e intercultural, la traducción literaria necesariamente forma parte de un contexto real y global, que se ha de considerar tanto en el proceso como en el resultado del proceso traslativo. En este sentido, Jones (2011: 156) afirma: "literary translators are often seen as 'communicators between cultures'. This trope embraces several different sub-metaphors, including cultural partisanship, intercultural embassy and globalized hybridity".

Resulta cuando menos llamativo que ambas ediciones de la Routledge Encyclopedia of Translation Studies (2001) apenas se haga referencia a los distintos géneros que pueden intervenir en la traducción literaria y que presentan una problemática diferenciada entre sí. Consideramos que existen tres categorías fundamentales:

- La traducción de textos literarios en prosa. En ella podríamos diferenciar dos tipos: la traducción académica o filológica (que incluye notas, aclaraciones o estudios sobre la obra traducida) y la traducción orientada al mundo editorial.

- La traducción de textos literarios en verso o traducción de textos poéticos. Existe en ella una subordinación permanente al plano formal del TO, que tiene tanta importancia como el propio contenido.

- La traducción de obras dramáticas. El teatro puede estar escrito en prosa o en verso, por lo que en ocasiones aúna las dificultades de las dos categorías previas. Asimismo, existen otros aspectos que se han de tener en cuenta en este tipo de casos como son, por ejemplo, la puesta en escena o la propia caracterización de los personajes. 


\section{La funcionalidad en traducción literaria}

Consideramos que las teorías funcionalistas resultan de gran utilidad para la traducción literaria, al igual que otros enfoques tradicionalmente utilizados en este ámbito, como los surgidos en los ámbitos filológico o lingüístico por citar tan solo dos de ellos. Sin embargo, no se ha recurrido de manera tan frecuente a las teorías funcionalistas, probablemente por la consideración de que el traductor no solo ha de transferir el mensaje del TO, sino también la forma específica en que dicho mensaje se expresa en la LO. Así, como señala Nord (1997: 8), "the theorists of equivalence tend to accept non-literal translation procedures more readily in translation of pragmatic texts than in literary translation". En esta línea, Reiss establece que la traducción literaria:

Orients itself towards the particular character of the particular work of art, taking as its guiding principle the author's creative will. Lexis, syntax, style and structure are manipulated in such a way that they bring about in the target language an aesthetic effect which is analogous to the expressive individual character of the source text. (Reiss, 1976: 21, traducido por Koller, 1989: 103)

A pesar de que las teorías funcionalistas y la Skopostheorie se desarrollan a partir de la segunda mitad del siglo pasado, el debate sobre la función o el propósito de la traducción ha sido una constante a lo largo de la historia, y muy especialmente los traductores de la Biblia ${ }^{8}$, por lo que uno de las afirmaciones más antiguas -y destacadas- al respecto la establece Cicerón en su De optimo genere oratorum: "In quibus non verbum pro verbo necesse. habui reddere, sed genus omne verborum vimque servavi. Non enim ea me adnumerare lectori putavi oportere, sed tamquam appendere".

No es hasta 1971 cuando Katharina Reiss ${ }^{10}$ introduce la categoría funcional en su aproximación objetiva a la crítica de la traducción. A pesar de que su obra Möglichkeitenund Grenzen der Übersetzungskritik esté claramente fundamentada en las teorías de la equivalencia, no cabe duda de que se trata del punto de partida de los Estudios sobre la Traducción ${ }^{11}$ en Alemania, así como de la denominada escue-

\footnotetext{
7 Acerca de la documentación sobre la obra del autor existen posturas enfrentadas, pues mientras que algunos traductores lo consideran un paso fundamental, otros prefieren traducir de un modo más "intuitivo", sin dejarse influir por elementos externos al TO.

${ }_{8}$ Tal es el caso de San Jerónimo o Martín Lutero donde en algunos fragmentos consideran que se ha de mantener incluso el orden de las palabras, mientras que en otros optan por ajustarse al sentido del original.

9 Se podría traducir del siguiente modo: "Si traduzco palabra por palabra el resultado será burdo, y si es necesario incluir cambios en el orden o en la formulación, parecerá que me he alejado de la función de un traductor".

10 Utilizamos aquí el apellido tal y como se le conoce en el mundo académico y en el conjunto de su bibliografía, si bien en alemán es Reiß.

11 Como ya señaló hace más de una década Hurtado Albir (1996: 151): “Actualmente, coexisten varios términos para denominar a la disciplina encargada de analizar la Traducción: en francés, 'Traductologie' y 'Théorie de la traduction'; en el mundo anglófono, 'Translation Theory', 'Science of Translation', 'Translation Studies', 'Traductology', 'Translatology'; en alemán 'Übersetzungstheorie', Übersetzungswissenschaft',
} 
la alemana. De acuerdo con esta autora, la traducción ideal sería aquella en la que "the aim in the TL [target language] is equivalence as regards the conceptual content, linguistic form and communicate function of a SL [source language] text" (Reiss 1989: 112). Este enfoque no excluye ciertas excepciones al requisito de la equivalencia, como podrían ser aquellos casos en los que el TM ha de tener un objetivo o una función diferente a la del $\mathrm{TO}^{12}$. Sin embargo, Reiss excluye estos casos de la traducción propiamente dicha y los considera como Übertragungen (que en español se podría traducir por "transferencia").

Si atendemos a una perspectiva esencialmente lingüística, como señalamos anteriormente el lenguaje literario se tiende a definir como una "desviación" o "alteración" de las normas de la comunicación ordinaria o como un uso creativo del sistema lingüístico. De este modo, tiene unas ciertas particularidades estéticas, expresivas o connotativas que responden generalmente a la intencionalidad del autor. La intencionalidad o propósito del autor puede producir un efecto estético o poético en el lector, de manera que es la interacción entre ambos -el binomio emisor-receptor- donde podemos enfatizar los enfoques funcionalistas. Nord establece (1997: 83), con todo, que "if we want to identify the translation-relevant features of a literary text, we can regard literary texts as ordinary texts with a few specific features that may become important for the translator". En este sentido, incluimos la traducción de su modelo de comunicación literaria ("Model of Literary Communication" de Nord, 1997: 83)

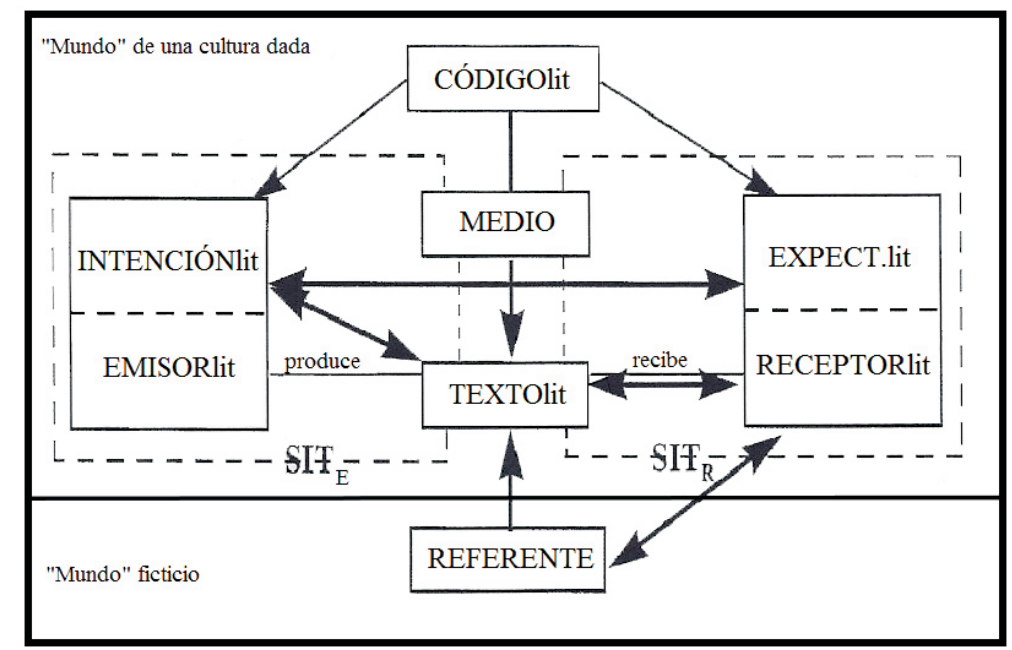

Figura 1: Modelo de comunicación literaria (traducción de Nord, 1997: 83)

\footnotetext{
'Translationswissenschaft'; en español 'Teoría de la traducción', 'Traductología', 'Translémica', 'Translatología', 'Estudios sobre la traducción', 'Estudios de la traducción', 'Lingüística aplicada a la traducción’...” En este trabajo optamos por priorizar el uso de 'Estudios sobre la traducción', siguiendo uno de los más utilizados en el contexto angloparlante: 'TranslationStudies'.

12 Tal sería el caso de, por citar tan sólo un ejemplo en el ámbito de la traducción literaria, las traducciones heterofuncionales en las que un clásico de la literatura se adapta para niños.
} 
Esta figura se explicaría del siguiente modo: un receptor (RECEPTORlit) tiene unas expectativas (EXPECT.lit) determinadas por la experiencia literaria previa. En una situación dada $\left(\mathrm{SIT}_{\mathrm{R}}\right)$, que tiene unas características temporales, de lugar e incluso una motivación propia, el receptor lee (o recibe) un texto (TEXTlit) producido por un emisor (EMISORlit) que tiene una intención literaria particular (INTENCIÓNlit). Existen marcadores, tanto internos como externos, que hacen referencia al código literario (CÓDIGOlit), que ayudan al receptor a comprender que se trata de un contenido literario. De igual modo, en el proceso de recepción del texto se pueden producir determinados efectos que podrían ser intencionados o no por parte del emisor. Sin embargo, lo que diferencia fundamentalmente esta comunicación de otros procesos comunicativos es, como señala Nord (1997: 84) que "the specific literary intention of the sender and the specific literary expectation of the receiver (...) are cultural-bond".

Por este motivo, la autora considera que su modelo incluye cuatro aspectos fundamentales en la comunicación literaria intercultural: la relación entre la intención del emisor y el texto, la relación entre la intención del emisor y las expectativas del receptor, la relación entre el referente y el receptor y, por último, la relación entre el receptor y el texto. Si se tienen en cuenta estos aspectos, es lógico llegar a la conclusión de que mantener la función y el efecto del texto literario original es una tarea compleja. Ante esta situación, tradicionalmente se han establecido dos posibilidades con respecto a la traducción: por una parte, un sector de los teóricos, encabezados por Ortega y Gasset, ha defendido la imposibilidad de la traducción; por otra, se puede afrontar la traducción basándose en la intuición y en el conocimiento del emisor y tratando de buscar un texto equivalente, que habría de ser juzgado como tal por parte de los receptores del texto literario. Sin embargo, el enfoque funcionalista propone una fundamentación teórica para la traducción literaria que permite al traductor justificar sus decisiones, de manera que el receptor del texto literario puede entender qué proceso se ha llevado a cabo durante la labor traductora y por qué. Para ello, la teoría del Skopos propone ciertas consideraciones generales aplicadas a la traducción literaria (Nord, 1997: 92s):

- El traductor interpreta el TO tanto con respecto a la intención del emisor como con respecto a su compatibilidad y adecuación en la situación meta. De este modo, el traductor compara las características del TM (tiempo, lugar, destinatarios, etc.) con las del TO, a fin de plasmar la intención del TO de acuerdo con la situación del TM. En este caso, la dificultad principal radica en conocer de la manera más cercana posible la intencionalidad del emisor del TO.

- El TM ha de conseguir reflejar la(s) función(es) del TO en la situación meta, sin olvidar la intención del emisor. Para ello, el traductor ha de determinar la(s) función(es) del TO para posteriormente tratar de conseguirla(s) en la cultura meta, para lo cual es necesaria una gran labor de documentación.

- El mundo del texto de la traducción ha de ser seleccionado de acuerdo con la intención que se pretende alcanzar en el TM. De este modo, el traductor debe decidir el grado de exotismo que se desea reflejar en el TM, esto es, ha de 
escoger entre la diversa gradación existente entre la domesticación y la extranjerización para su traducción.

- El código ha de seleccionarse de modo tal que el efecto del TM se corresponda con la(s) función(es) del TM, puesto que la cultura meta proporciona unos medios lingüísticos adecuados para conseguir una función determinada. Así, los receptores del TM identificarán la intención de la traducción y, por consiguiente, recibirán el TM con la función deseada.

\section{Críticas a la aplicación de las teorías funcionalistas a la traducción literaria}

Las consideraciones expuestas anteriormente ponen de relieve el hecho de que la traducción es un proceso continuo de toma de decisiones $\mathrm{y}$, por este motivo, la elección de una opción u obra afecta inevitable y necesariamente al efecto del texto traducido. No obstante existen diversas críticas hacia los enfoques funcionalistas entre las que destacamos fundamentalmente dos: por una parte, hay críticos que defienden que no todas las acciones tienen una intención; por otra, otro sector afirma que la Skopostheorie no respeta el TO.

Con respecto a la primera objeción, el propio Vermeer (1989: 177ss; citado en Nord, 1997: 110) señala: "Behaviour that does not show any intentionality or purpose is thus not regarded as an action". Si se considera la comunicación como un todo, es posible que las acciones no tengan una finalidad en sí mismas, pero los receptores sí las interpretan como acciones motivadas. En este sentido, el objetivo o la finalidad se puede considerar en el contexto de los Estudios sobre la Traducción con respecto al conjunto del proceso traductor, con respecto a una unidad de traducción determinada y la estrategia de traducción seguida en el proceso traductor, o con respecto al TM como resultado final.

$\mathrm{Si}$ atendemos a la segunda objeción señalada por los críticos de las teorías funcionalistas, que establecen que las teorías funcionalistas no respetan el TO, se fundamentan en el hecho de que cuando el traductor considera las expectativas y necesidades del receptor se pierden elementos claves del TO. Nord (1997:1997) ante esta situación defiende lo siguiente:

To answer this criticism, I should point out that functionalist approaches are what a text is. The form in which the source text lies before the translator is a product of the many variables of the situation (time, place, addressees) in which it originated, and the way thus form is interpreted and understood by the translator or any other receiver is guided by the variables of the new reception situation, including, of course, the translator's competence in text analysis, which may help them to relativize their own standpoint.

En esta misma línea se sitúan los traductores y críticos literarios que consideran las teorías funcionalistas como un enfoque alejado de su ámbito. Así, mientras consideran que sí podían ser útiles para los textos técnicos, por ejemplo, para la traducción literaria defienden que es poco útil debido a que el TO tiene un estatus 
diferente, No obstante, los cuatro principios señalados anteriormente son perfectamente válidos para la traducción literaria y, adecuación, como establece Nord (1997: 122):

To make the originality of the source show through in the target text is, of course, a possible translation purpose. The problem is whether this can be done by simply reproducing what is in the text, since what is original in one culture may be less so in another, and vice versa.

Asimismo, no se debe olvidar que en los enfoques funcionalistas también se encuentra presente el concepto de fidelidad, que algunos de los críticos tienden a obviar dependiendo de la postura que defiendan. En este sentido, no cabe duda de que el traductor literario necesariamente debe respetar el TO durante la interacción traslativa, atendiendo tanto al estilo del autor como al contenido. Este concepto de fidelidad en los enfoques funcionalistas aplicados a la traducción literaria muestra, por tanto, la compatibilidad de ambas ideas, puesto que el escopo -el propósito- del TM ha de ser compatible con la intencionalidad del/de los autor/es del TO.

\section{Conclusión}

Con todo lo señalado anteriormente, consideramos que las teorías funcionalistas pueden resultar de gran utilidad en el desarrollo actual y futuro de los Estudios sobre Traducción, puesto que en el caso de la traducción literaria permiten analizar el propio proceso traductor más allá de la mera intuición del traductor (que, evidentemente, también es necesaria). Por este motivo, consideramos de gran utilidad emplear este enfoque para realizar un modelo de análisis traductológico, a fin de mostrar en él no sólo los aspectos lingüísticos o culturales del TO y del TM, sino también las distintas estrategias traductoras.

Gracias a la aproximación funcionalista, el receptor del texto literario puede intuir no solo el propio proceso traductor seguido para producir una unidad de traducción o un TM dado, sino también la justificación de la adopción de una elección o decisión determinada, esto es, la traducción como proceso y la traducción como resultado en un contexto cultural determinado. La adopción de nuevos enfoques para la traducción literaria, que complementen a los ya establecidos filológico y lingüístico, permite la incorporación de nuevos elementos de innovación en los Estudios sobre la Traducción con los que afrontar los retos que se derivan continuamente de las interacciones interlingüísticas e interculturales.

\section{Referencias bibliográficas}

Aguiar e Silva, V. M. de, Teoría de la Literatura. Versión española de Valentín García Yebra. Madrid: Gredos 1975.

Baker, M. (ed.), Routledge Encyclopedia of Translation Studies. London / New York: Routledge 2001. 
Baker, M. y G. Saldanha (eds.), Routledge Encyclopedia of Translation Studies. Second Edition. London / New York: Routledge 2011.

Bush, P., «Literary Translation», en: Baker, Mona (ed.), Routledge Encyclopedia of Translation Studies. London / New York: Routledge 2001, 127-130.

Campos Plaza, N. y E. Ortega Arjonilla, Panorama de Lingüística y Traductología. Cuenca / Granada: Ediciones de la Universidad de Castilla-La Mancha / Editorial Atrio 2005.

García Yebra, V., Teoría y práctica de la traducción. Madrid: Gredos 1982.

García Yebra, V., Traducción: historia y teoría. Madrid: Gredos 1994.

Guglielni, M., «La traducción literaria», en: Gnisci, A. (ed.). Introducción a la literatura comparada. Traducción de Luigi Giuliani. Barcelona: Editorial Crítica 2002, 291-344.

Hurtado Albir, A., «La traductología: lingüística y traductología», Trans. Revista de Traductología 1 (1996), 151-160.

Hurtado Albir, A., Traducción y traductología: Introducción a la traductología. Madrid: Cátedra 2011.

Jakobson, R., «On Linguistic Aspects of Translation», en: Brower, R. (ed.), On Translation. Cambridge: Mass 1959, 232-239.

Jones, F. R., «Literary Translation», en: Baker, M. y G. Saldanha (eds.), Routledge Encyclopedia of Translation Studies. Second Edition. London / New York: Routledge 2011.

Koller, W., «Equivalence in translation theory», en: Chesterman, A. (ed.), Readings in Translation. Helsinki: Finn Lectura 1989, 99-104.

Lefevere, A., Translating Literature: Practice and Theory in a Comparative Literature Context. New York: The Modern LanguageAssociation of America 1992.

Marco Borillo, J. et alii, «La traducción literaria», en: Hurtado Albir, A., Enseñar a traducir. Metodología en la formación de traductores e intérpretes. Madrid: Edelsa 1999, 167181.

Molina, L. y A. Hurtado Albir. «Translation techniques revisited: A Dynamic and Functionalist Approach», Meta, XLVII, 4 (2002), 498-512.

Nord, C., Translating as a Purposeful Activity. Functionalist Approaches Explained. Manchester: St. Jerome Publishing 1997.

Nord, C., Text Analysis in Translation. Theory, Methodology, and Didactic Application of a Model for Translation-Oriented Text Analysis. Second edition. Amsterdam/New York: Rodopi 2005.

Rabadán Álvarez, R., Equivalencia y traducción: Problemática de la equivalencia translémica inglés-español. León: Universidad de León 1991.

Reiss, K., Translation Criticism - The Potential and Limitations. Categories and Criteria for Translation Quality Assessment. Translated by E. F. Rhodes. Manchester: St. Jerome 2000.

Sánchez, M. T.,The Problems of Literary Translation. A Study of the Theory and Practice of Translation from English into Spanish. Bern: Peter Lang 2009.

Toury, G., "'Translation of literary texts' vs. 'literary translation’: A distinction reconsidered», en: Tirkkonen-Condit, S. y J. Laffling (eds.), Recent Trends in Empirical Translation Research. Joensuu: JoensuunYliopisto - University of Joensuu 1993.

Valéry, P., Cahiers, $t$. II. Paris: Centre National de la Recherche Scientifique 1988.

Venuti, L. (ed.), The Translation Studies Reader. London / New York: Routledge 2004.

Vidal Claramonte, M. C. Á., El futuro de la traducción. Últimas teorías, nuevas aplicaciones. Valencia: Institución Alfonso el Magnánimo 1998.

Vilnay, J.-P. y J. Darbelnet, Stylistique comparée du Français et de l'Anglais. Méthode de traduction. Paris: Didier 2004. 